\title{
CHRISTIAN HERRGEN Y LA INSTITUCIONALIZACIÓN DE LA MINERALOGÍA EN MADRID
}

\author{
Dolores Parra \\ Francisco Pelayo
}

Dpto. de H." de la Ciencia - Centro de Estudios Históricos, CSIC - C/ Duque de Medinaceli 6, Madrid

\section{RESUMEN}

Uno de los objetivos de la política científica de los gobiernos borbones fue la de potenciar aquellas disciplinas susceptibles de ser aplicadas en el necesario fomento de la economía española. Tal fue el caso de la Mineralogía, ciencia que fue desarrollada e impartida en varias instituciones científicas ilustradas. Uno de estos centros fue el Gabinete de Historia Natural de Madrid, en el que la labor del especialista alemán Christian Herrgen contribuyó a la institucionalización de la mineralogía española.

\section{SUMMARY}

One of the goals of the scientific policy of the governments of the Borbones were that of favors the disciplines subject to be applied for the necessary stimulus of the Spanish economy. Such it was the case of the Mineralogy, science that was developed and imparted in several scientific cultured institutions. One of these centers were the Cabinet of Natural History from Madrid, in which the work of the German specialist Christian Herrgen contributed to the institutionalization of the Spanish Mineralogy.

\section{INTRODUCCIÓN}

La reforma política y administrativa defendida por la dinastía borbónica en España durante el siglo XVIII, semejante a la establecida por el modelo ilustrado francés, se concretó en el ámbito científico en una serie de proyectos de centralización, modernización y creación de nuevas estructuras.

Los sucesivos gobiernos de los monarcas borbones, conscientes de la necesidad de introducir los conocimientos científicos y tecnológicos en su política ilustrada, diseñaron un programa, de clara influencia francesa, basado fundamentalmente en los siguientes puntos: 


\section{DOLORES PARRA Y FRANCISCO PELAYO}

- la creación de instituciones científicas para organizar la ciencia, tales como Academias científicas, Gabinetes de Historia Natural, Jardines botánicos..., espacios en los que se discutirían las nuevas ideas, se realizarían experiencias y ensayos científicos, se impartiría la enseñanza de disciplinas científicas y en donde se conservarían, identificarían y estudiarían las especies recogidas y enviadas por los colectores.

- la contratación de técnicos y especialistas extranjeros, para que fueran introduciendo los nuevos conocimientos en ciencia y tecnología europeas.

- la dotación de pensiones para viajes de ampliación de estudios a Europa. Si las instituciones científicas de París fueron los establecimientos más visitados por los alumnos españoles deseosos de profundizar en los fundamentos teóricos y empíricos de las ciencias naturales, los centros mineros alemanes y suecos coparon el interés de los pensionados interesados en la adquisición de conocimientos tecnológicos en las ciencias de la Tierra ${ }^{1}$.

- la financiación de expediciones científicas a América, con el objeto de recopilar, inventariar y evaluar la posible explotación económica de los recursos naturales de los dominios coloniales.

En el marco de este proyecto ilustrado estaba previsto que el cumplimiento de estas premisas confluyera en una estructura científica centralizada en la Corte, de modo que una vez creadas las instituciones y encomendada a los especialistas extran-

1 La intervención estatal en el envío de pensionados españoles a Europa tuvo lugar desde mediados del siglo XVIII. Artífice de esta política fue Zenón de Somodevilla, marqués de la Ensenada (17021781), Secretario encargado de los Despachos de Guerra, Marina, Hacienda e Indias con Fernando VI. En los primeros años de la década de los cincuenta, Ensenada envió a diversos comisionados, entre ellos a Jorge Juan y a Antonio de Ulloa, para que tomaran nota de los modernos conocimientos tecnológicos (Cf. LAFUENTE, A. y PESET, J.L. (1981), «Política científica y espionaje industrial en los viajes de Jorge Juan y Antonio de Ulloa», en Mélanges de la Casa de Velázquez, Madrid, XVII, pp.233-262). En realidad, más que realizar un aprendizaje lo que pretendió Ensenada fue que efectuaran misiones de espionaje industrial (Sobre este tema puede verse Helguera Quijada, J. (1988), «Las misiones de espionaje industrial en la época del Marqués de la Ensenada, y su contribución al conocimiento de las nuevas técnicas metalúrgicas y artilleras, a mediados del siglo XVIII» en M. Esteban Piñeiro et al. (Coordinadores), Estudios sobre historia de la ciencia y de la técnica, Junta de Castilla y León, Valladolid, vol.II, pp.671695). El envío de pensionados a Europa fue máximo durante el reinado de Carlos III. Desde finales de los años sesenta, y a lo largo de las dos décadas siguientes, familias de nobles y Sociedades ilustradas imitaron el proceder del Estado y financiaron el envío de pensionados, que fueron generalmente a París, Centroeuropa y Escandinavia a completar estudios, constituyendo a su vuelta el núcleo de ilustrados a través del cual se desarrolló una parte del programa de renovación científica en España y en sus posesiones americanas (Cf. PELAYO, F. (1990), «La adquisición de las técnicas mineras en la España de la Ilustración (1770-1800)», en Fernández Pérez, J. \& GONZÁlez TASCÓN, I., Ciencia, Técnica y Estado en la España Ilustrada, M.E.C., Zaragoza, pp.73-87). 
jeros la difusión de las nuevas disciplinas, fueran los pensionados quienes a su vuelta asumieran estas funciones ${ }^{2}$.

El caso de la mineralogía puede considerarse como un buen ejemplo de la politíca científica ilustrada. En el desarrollo de la minería y la mineralogía en España durante los últimos años del Antiguo Régimen aparecen todas las características antes citadas: pensionados, creación de instituciones de investigación y enseñanza, formación de colecciones españolas, expediciones mineralógicas al Nuevo Mundo y contratación de expertos extranjeros encargados de la enseñanza de la disciplina.

\section{LOS PROYECTOS ILUSTRADOS DE INSTITUCIONALIZACIÓN CIENTÍFICA}

Puede decirse que durante las primeras décadas de la centuria, en un período de tiempo que coincide, poco más o menos, con el reinidido de Felipe V, se pusieron las bases de la política científica ilustrada, que se desarrolló posteriormente en la segunda mitad del siglo.

Para el pensamiento reformista ilustrado estaba claro que el necesario fomento de la Agricultura, el Comercio, la Navegación y las Manufacturas pasaba por el «adelantamiento de las Ciencias y las Artes». Para conseguir esto era necesario disponer de unas instituciones científicas centralizadas en la corte, siguiendo el modelo de la Académie Royale des Sciences y del Jardin du Roi de París, en donde sus miembros pudiesen realizar experiencias, discutir problemas y acopiar información y materiales científicos enviados por corresponsales periféricos, tanto continentales como coloniales.

Ya en las primeros años del siglo XVIII se propusieron proyectos para crear instituciones científicas ubicadas en la corte. El propio Felipe V emitió una Real Orden en la que anunciaba el establecimiento de una Biblioteca cercana a Palacio. Para contribuir al desarrollo de las investigaciones físicas y médicas tendrían cabida en la mencionada Biblioteca Real «las cosas singulares, raras y extraordinarias que se hallan en las Indias y partes remotas», por lo que se ordenaba a todas las autoridades políticas, desde virreyes hasta gobernadores y corregidores, y a toda persona, civil o eclesiástica, que recogieran y enviaran a la Corte ejemplares botánicos, zoológicos y mineralógicos ${ }^{3}$.

\footnotetext{
2 Un magnífico estudio del proceso de institucionalización científica en España durante el siglo XVIII es el de LAFUENTE, A. y PESET, J.L. (1988), «Las actividades e instituciones científicas en la España ilustrada», en Sellés, M., PESET, J.L. y LAFUENTE, A. (compiladores), Carlos III y la ciencia de la Ilustración, Alianza Editorial, Madrid.

3 Archivo General de Indias (A.G.I.), Indiferente General, leg. $n^{\circ} 614$.
} 
Esta Biblioteca Real fue la base del proyecto del benedictino Martín Sarmiento (1695-1772), para difundir los nuevos conocimientos mediante un proceso de institucionalización científica. Sarmiento, en sus «Reflexiones literarias para una Biblioteca Real (1743)» $\rangle^{4}$, sugería que los cuatro baluartes del edificio destinado a la Biblioteca Real estuviesen reservados a un Observatorio astronómico y a las Reales Academias de la Lengua, Historia y Medicina, respectivamente. En ésta última proponía la realización de observaciones y de experiencias de física, botánica, farmacia, química, etc. El Observatorio astronómico estaría dedicado al estudio de la cosmografía, las matemáticas, la mecánica... A las restantes Academias se podían agregar la arquitectura, la pintura y demás Bellas Artes. De esta forma, todo el edificio se convertiría en el «Palacio de la Sabiduría», como el templo de Santa Sofía en Constantinopla o el Colegio de la Sapiencia en Roma, pudiendo denominársele, según Sarmiento, el «Real Palacio de Palas o Minerva», en honor de esta diosa, la Atenea de los griegos, símbolo del progreso intelectual.

También en estas primeras décadas del siglo XVIII hubo diversas propuestas, como las del marqués de Villena, Melchor de Macanaz ${ }^{5}$ o Jerónimo Ustáriz ${ }^{6}$, para intentar crear una Academia de Ciencias y Artes en Madrid.

A lo largo de la segunda mitad del siglo, principalmente durante el reinado de Carlos III, la política científica ilustrada se desarrollaría con la intervención del Estado en los apartados citados al principio.

Así, a comienzos de la década de los cincuenta, se proyectaron la creación de dos Academias de Ciencias, una vinculada a José de Carvajal (1698-1754), Secretario de Estado, encargado de Asuntos Exteriores, en la que intervino el poeta Ignacio de Luzán (1702-1754) ${ }^{7}$, y otra, propuesta originariamente desde la Academia Médica Matritense, cuyas ordenanzas fueron redactadas como Sociedad Real de Ciencias de Madrid, por un grupo de profesores y cirujanos de la Armada, como Jorge Juan,

4 Este folleto se publicó en el Semanario Erudito, t.XXI, 1789, pp.99-273.

5 Melchor de Macanaz (1670-1760), Fiscal General del Reino, recomienda el establecimiento de una Academia de Ciencias y Artes en su obra redactada en 1722 «Auxilios para bien gobernar una Monarquía católica», publicada años después en el Semanario Erudito, 1787, t.V, pp.217-203.

6 Jerónimo de Ustariz (1670-1732), miembro del Consejo del rey y de la Real Junta de Comercio, publicó en su Theorica y Practica de Comercio y Marina, Madrid, 1724, p.24, la conveniencia de establecer en España Academias en las que «se especulan, ensayan y adelantan diversas Ciencias y Artes».

7 Véase RocA, P. (1913), «Orígenes de la Real Academia de Ciencias Exactas, Físicas y Naturales (Historia científica del primer Gobierno de Fernando VI)», en Homenaje a Menéndez y Pelayo, t.II, pp.845-940; OzANAM, D. (1962), «L'ideal académique d'un poète éclairé: Luzan et son projet d'Académie Royale des Sciences, Arts et Belles Lettres», Bulletin Hispanique, LXIV, pp.188-208; y CARNERO, G. (1989), «El Plan de una Academia... de Ignacio de Luzán», Nueva Revista de Filología Hispánica, XXXVII, pp.159-201. 
Louis Godin (1704-1760), José Carbonel y Pedro Virgili (1699-1766), cercanos al marqués de la Ensenada ${ }^{8}$.

\section{LOS INICIOS DE LA INSTITUCIONALIZACIÓN DE LA MINERALOGÍA}

Tras el descubrimiento de la platina por Ulloa en el virreinato de Nueva Granada (actual Colombia), y la fuerte demanda europea que acompaña a este hallazgo, España era el único dueño de las minas conocidas de este metal. Por otro lado, la arquitectura social e institucional española, pacata en la potenciación de nuevas estructuras productivas y socioeconómicas, se manifiestaba incapaz de potenciar la explotación del metal noble. No había política gubernamental para la platina que verá así reducido su papel al de mero elemento de intercambio, dentro de la alianza científica establecida con Francia ${ }^{9}$, utilizada principalmente para atender peticiones de embajadores extranjeros, científicos, gabinetes de Ciencias Naturales o particulares.

Si nos remontamos a los primeros intentos de potenciar la producción rentable y eficiente de la platina, hay que referirse a Ulloa y al conde de Peñaflorida, como los actores sociales que propiciaron desde sus comienzos este desarrollo. El primero de ellos fundó en Madrid, en el año 1752, el Laboratorio Metalúrgico llamado «Real Casa de la Geografía y Gabinete de Historia Natural», conocido popularmente como «Casa del platino», primera institución española en su género. Ulloa organizó este establecimiento con la ayuda de especialistas europeos, como el irlandés William Bowles (1705-1780), los alemanes A. J. Keterlin y el francés A. de La Planche, éstos últimos encargados de efectuar ensayos y experimentos químicos y metalúrgicos ${ }^{10}$. El proyecto finalizó cuatro años después de su apertura, fecha en que la platina ya era objeto de análisis científico por los químicos más de célebres de Europa.

Habrán de trancurrir desde entonces diez años hasta que se dispusiera la apertura del Real Seminario Patriótico de Vergara. Esta institución se estableció dentro de la

\footnotetext{
8 Puede verse Efemérides de España, viernes 18 de mayo de 1804, n 139, pp.571-574 y sábado 19 de mayo de 1804, $\mathrm{n}^{\circ}$ 140, pp.576-578; GUILLÉN TATO, J. (1941), «Juan y Ulloa y los precedentes del XVIII de la Real Academia de Ciencias de Madrid», Revista de la Real Academia de Ciencias Exactas, Físicas y Naturales, ${ }^{\circ} 34$, pp.440-461; y TORROJA, J.M. (1973), «Jorge Juan y los antecedentes de la Real Academia de Ciencias Exactas, Físicas y Naturales», Revista de la Real Academia de Ciencias Exactas, Físicas y Naturales, t.LXVII, pp.11-25.

9 Cf. PUERTO, F.L. (1988), La ilusión quebrada: botánica, sanidad y política científica en la España ilustrada, Serbal-CSIC, Madrid, pp.154-157; Capitán Vallvey, L.F.(1994), «Platina española para Europa en el siglo XVIIl», Llull, vol. 17, p.296.

10 Sobre los orígenes del Gabinete de Historia Natural de Madrid puede consultarse Calatayud Arinero, $M^{\mathrm{a}}$ A. (1986), «Antecedentes y creación del Real Gabinete de Historia Natural», Arbor, $\mathrm{n}^{\circ} 482$, t. CXXIII, pp.9-33.
} 
Real Sociedad Vascongada de Amigos del País ${ }^{11}$, fundada por Javier María de Munibe, conde de Peñaflorida, y fue uno de los vehículos introductores de la mineralogía como tal disciplina en España. A través del viaje de aprendizaje realizado por uno de los hijos de Peñaflorida, Ramón María Munibe (1751-1774)12, la Sociedad Vascongada mantuvo relaciones científicas con los centros mineros europeos más prestigiosos, tales como la Universidad de Upsala, el Colegio de Minería de Estocolmo y las principales ferrerías suecas, así como la Escuela de Minas de Freiberg. Además, se crearon dos cátedras de Física y Química que, dado el carácter novedoso de sus disciplinas, regentarían dos franceses: Francisco Chavaneau (1754-1842) y Louis Proust (1754-1826). Apenas transcurrido año y medio, Chavaneau se hizo cargo de las funciones de Proust, que cambió su destino por el Laboratorio de Química de Segovia. Chavaneau, por su parte, quedó encargado del proyecto de investigación sobre la purificación del platino. Los experimentos se realizaron en colaboración con Fausto de Elhuyar (1755-1833) y el marqués de Narros y dieron sus frutos en el año 1786, al descubrirse el modo de aislar el platino, además del proceso metalúrgico de hacerlo dúctil y maleable.

Pero este importante logro científico no sería suficiente para justificar el asentamiento definitivo de la disciplina mineralógica. De hecho, la cátedra desaparecería en el año 1784 y no reaparecería hasta pasados nueve años y esta vez sólo con un año de duración, debido ahora a la invasión del País Vasco por las tropas francesas.

LA COLECCIÓN MINERALÓGICA DE FRANCO DÁVILA Y LOS COLECTORES DEL REAL GABINETE DE HISTORIA NATURAL

En el año 1767, el ciudadano de Guayaquil Pedro Franco Dávila (1711-1786) ofreció a la Corona española su Gabinete de Historia Natural. Dávila, que en esos momentos se encontraba en París, ya había tenido noticias en 1753 que el rey de España, influido por Ensenada, estaba interesado en formar una colección de objetos de Historia Natural y antigüedades. Por ello, hizo un inventario de los ejemplares de su colección, por si Ensenada estaba interesado en adquirirla. De todas formas, Dávi-

1 Véase Sarrailh, J. (1957), La España ilustrada de la segunda mitad del siglo XVIII, Fondo de Cultura Económica, México, pp.230-251.

12 Acerca del viaje de Ramón María Munibe puede verse Urquijo, J. (1929), Los amigos del País, Imp. Diputación de Guipúzcoa, San Sebastián, pp.42-89; «Cartas de don Ramón Mª Munibe a su padre don Xavier y a la Real Sociedad Bascongada de los Amigos del País», en Colección de documentos para la historia de Guipúzcoa, nº 6, San Sebastián, 1965, pp.39-77. 
la hubo de esperar varios años hasta que en 1771 Carlos III adoptó la resolución de comprar su gabinete ${ }^{13}$.

Tras la compra de la colección de Dávila, éste fue nombrado director del Real Gabinete de Historia Natural, que se creó en 1776, y se dispuso que se instalase en el mismo edificio donde se encontraba la Real Academia de las Tres Nobles Artes. La inauguración al público tuvo lugar el 4 de noviembre de 1777.

El organigrama del Gabinete en su origen estaba encabezado por Dávila, que ejercía las funciones de director; Eugenio Izquierdo, en ese momento pensionado en París para ampliar conocimientos en Ciencias Naturales, era el vicedirector; José Clavijo y Fajardo (1726-1806), el formador de índices; y Francisco de Eguía el disecador, cargo que pasó a Juan Bautista Bru (1740-1799)14.

Dávila, cuyos ejemplares constituyeron el núcleo de las colecciones mineralógicas del nuevo Gabinete ${ }^{15}$, murió a comienzos de 1786. Se nombró para sustituirle a Eugenio Izquierdo, mientras que a Clavijo se le ascendió a Vicedirector. Pero como Izquierdo, por las relaciones y contactos que había establecido durante su estancia en Francia, solía estar muy ocupado en asuntos diplomáticos, prácticamente era Clavijo quien dirigía el Gabinete. A él le corresponde el mérito de haber impulsado, desde la administración del Gabinete, la formación de colecciones mineralógicas y la enseñanza de la mineralogía.

El desarrollo de la mineralogía en el Gabinete durante sus primeras décadas estuvo vinculado al interés que mostró por el fomento de esta disciplina Clavijo y Fajardo. Este naturalista canario había entrado en el Gabinete gracias a sus anteriores puestos en la Administración estatal, primero como Oficial de Archivo de la Primera Secretaría de Estado (1763) y luego como director de los teatros de los Reales Sitios (1770) y encargado de la publicación del Mercurio Histórico y Político de Madrid (1773). Por último, en 1777 fue nombrado para el citado cargo de Formador de Indices en el Real Gabinete ${ }^{16}$.

\footnotetext{
13. Véase Calatayud, Ma A. (1988) Pedro Franco Dávila y el Real Gabinete de Historia Natural, CSIC, Madrid.

14 Una buena historia del Real Gabinete de Historia Natural, actualmente Museo de Ciencias Naturales de Madrid, se puede encontrar en Barreiro, A. (1992), El Museo Nacional de Ciencias Naturales (177I-1935), Doce Calles, Aranjuez.

15 Cf. Amorós, J.L. (1963), «Notas sobre la historia de la cristalografía y mineralogía III. Las colecciones del caballero Franco Dávila y el origen del Real Gabinete de Historia Natural», Boletín de la Real Sociedad de Historia Natural, (G.), 61, pp.9-37.

16 Sobre la biografía de J. Clavijo y Fajardo puede consultarse, entre otras obras, a Millares Carlo, A. (1932), Ensayo de una bio-bibliografía de escritores naturales de las Islas Canarias (Siglos XVI, XVII y XVIII), Madrid, Biblioteca Nacional, pp.176-186; y EsPINOSA, A. (1970), Don José Clavijo y Fajardo, Cabildo Insular de Gran Canaria.
} 
Las colecciones del Real Gabinete fueron incrementándose poco a poco gracias, por un lado, a los envíos que llegaban desde todos los rincones de los dominios geográficos españoles y, por otro, a las actividades de los colectores vinculados a la institución. En este sentido, hay que señalar la labor llevada a cabo por los colectores Francisco Xavier Molina y Juan Palafox Rovira, a quienes se comisionó para que realizaran varias excursiones por la península, a fin de que reunieran colecciones zoológicas y mineralógicas que completaran las existentes en el Gabinete. Ambos preparararon materiales zoológicos, petrificaciones y minerales de Madrid, Granada, Almería, las minas de Almadén y Córdoba ${ }^{17}$.

Un ejemplo del interés existente en la dirección del Gabinete por conseguir unas buenas colecciones mineralógicas fue la comisión que se le encargó en 1791 a Molina, para que pasara a Conil y asistiera a la extracción del azufre cristalino ${ }^{18}$. En este yacimiento ya se habían extraído muestras de azufre cristalizado en 1772 y 1773 , pero, trasladadas a Madrid, habían llegado en mal estado. Se encargó entonces a Molina que recogiera ocho o diez cajones de muestras de azufre, por ser éste un mineral muy apreciado por los gabinetes europeos. A pesar de las dificultades que le puso a Molina el duque de Alba, dueño de los terrenos donde se encontraba el yacimiento, que se negó a que los costos de la extracción fueran a su costa, Molina remitió al final siete cajas de ejemplares al Gabinete.

El Rel Gabinete, uno de los mejores de Europa en su género, continuó aumentando sus colecciones mediante la recogida de ejemplares mineralógicos raros, a poder ser duplicados, que a su vez permitía el intercambio con otros gabinetes. Esto exigía que los colectores tuviesen unos mínimos conocimientos y una formación en mineralogía que les permitiera seleccionar las muestras que tenían interés y desechar las más comunes. Para cubrir esta parcela se recurrió a colectores alemanes, dada la tradición que existía en este país por el estudio teórico y práctico de la mineralogía y minería.

Así, en 1793 los hermanos Enrique y Guillermo Thalaker fueron contratados como colectores de minerales ${ }^{19}$. Los Thalaker realizaron una primera excursión en la sierra de Guadarrama y otras localidades de la comunidad madrileña, como Aranjuez, Cercedilla y Navacerrada. Posteriormente, Guillermo Thalacker, que sería colector del Gabinete entre 1799 y 1802, realizó un viaje por Guadalajara, recogiendo muestras de titanio en Horcajuelo.

\footnotetext{
17 Archivo del Museo Nacional de Ciencias Naturales (AMNCN) Gabinete Leg. $n^{\circ}$ 7, carp. 1 y Caja grande $\mathrm{n}^{\circ} 9$, carp. 5 .

18 Cf. BARREIRO, A. (1992), pp.83-87.

19) Acerca de Juan Guillermo Thalacker véase MAFFeI, E. y RUA FiguerOA, R. (1871-2), Apuntes para una Biblioteca Española de libros, folletos, y artículos, impresos y manuscritos, relativos al conocimiento y explotación de las riquezas minerales, Madrid, 2 vols., vol. II, pp.189-190.
} 
Unos años después, Clavijo comisionó a Guillermo Thalaker con el objeto de que recorriera España y recogiera muestras de minerales para el Gabinete. Uno de estos viajes lo llevó a cabo entre Madrid y Teruel, pasando por Alcalá, Guadalajara, Torija, Algora, Alcolea, Luzón, Asella, Molina de Aragón, Ródenas, Cella y Teruel ${ }^{20}$.

La posibilidad de mejorar las colecciones mineralógicas se planteó a través del proyecto presentado por Molina, a comienzos de 1793, para pasar a América y formar colecciones zoológicas para el Gabinete. A Clavijo le pareció una buena idea y añadió que era necesario disponer también de una colección de minerales americanos, ya que se habían enviado muchos ejemplares de aquel continente sin hacer una selección de los que eran más estimados e interesantes para el Gabinete. Clavijo, por tanto, sugirió que se aprovechara la expedición para enviar a algunos especialistas en mineralogía.

Los mineralogistas designados para esta expedición fueron dos colectores alemanes: los hermanos Christian y Conrad Heuland. Habían entrado en contacto con la institución en 1792, ofreciendo la venta de la colección mineralógica de su tío Jacob Foster. Christian Heuland presentó un escrito indicando la pobreza del Gabinete en cuanto ejemplares de minerales americanos que, sin embargo, podían encontrarse tanto en otros gabinetes como en manos de particulares.

La propuesta de los Heuland para pasar a América e intentar paliar la escasez de material mineralógico del Gabinete, que coincidía con la de Molina, le pareció muy oportuna a Clavijo. Afirmaba que con los minerales que recogiese Heuland en América el Gabinete estaría tan bien dotado que superaría en existencias a cualquier otro. Así, en lugar de tener que «mendigar» ejemplares en los gabinetes extranjeros, éstos tendrían que ofrecer al Real Gabinete los suyos más raros para intercambiar con los de esta institución.

Clavijo puso una limitación y era que los Heuland se debían ceñir a una «Instrucción» redactada por él, en la que se describiría cuál debía ser concretamente su actividad mineralógica en las colonias americanas.

En la «Instrucción» se señalaba que el objetivo final de los comisionados al pasar a América era, evidentemente, recolectar minerales, cristalizaciones, fósiles y conchas para el Real Gabinete de Historia Natural. Pero se detallaban también una serie de cuestiones, en algunos casos obligaciones, a las que se tenían que ajustar. La primera de ellas era la de redactar una «Historia Físico Mineralógica de aquellos Reynos». En otros artículos de la «Instrucción» se designaba a Christian como primer comisionado, mientras que Conrad iba en calidad de asociado para ayudarle y sustituirle en el caso de fallecimiento. Tenían que trabajar reconociendo el terreno donde se hallasen, estudiando su geografía física, describiendo su situación, tipo de terreno,

20) Thalacker, G. (1800), «Observaciones geognósticas que... hizo en su viaje desde esta corte a Teruel, ordenadas por D. Christian Herrgen», Anales de Historia Natural, t.II, pp.281-314. 
clima, etc. También incidirían en el estudio de las minas registradas, el método utilizado para su beneficio, su estado actual, cantidad que producía en el presente (si aumentaba o disminuía su producción), su rendimiento, etc., ocupándose asimismo de las minas abandonadas y de las causas que habían llevado a tal estado. Debían recoger los fósiles, petrificaciones y cristalizaciones que se encontraran tanto en los afloramientos superficiales como los hallados en los yacimientos excavados. Tenían que fijarse también en los aspectos geológicos, como «la dirección de las montañas y la materia y colocación de sus diferentes capas», observando estas últimas en los márgenes de los ríos, en los barrancos, minas y excavaciones, ocupándose en general de todos los accidente geográficos.

La formación de colecciones era una de las labores más importantes que los Heuland tenían que realizar. De las muestras más raras recogerían varios ejemplares, y si descubrían algún tipo de ejemplar desconocido debían reunir un elevado número de muestras que sirvieran para intercambiar con los gabinetes de otros países.

Aunque en la «Instrucción» se insistía en que los comisionados tenían que recoger aquellos ejemplares singulares que faltaban en el Gabinete de todos los lugares por los que pasasen, se señalaban algunas localidades y determinados minerales, en los que especialmente debían de centrarse. Los últimos artículos de la «Instrucción» se referían a la denominación indígena, ajustada a la nueva nomenclatura química de los ejemplares recogidos y haciendo referencia a donde se hubieran encontrado; la formación de un diario y de un catálogo que enviarían periódicamente al Gabinete en distintos barcos, etc. ${ }^{21}$

\section{LA REAL ESCUELA DE MINERALOGÍA}

El aislamiento de la platina en Vergara le valió a Chavaneau el inmediato traslado a Madrid, donde en el año 1789 se fundó la Real Escuela de Mineralogía de Indias²2, financiada por el Ministerio de Hacienda, de la que el científico francés sería catedrático. El objetivo de esta nuevo establecimiento era instruir a los jóvenes españoles

21 Sobre la expedición de los hermanos Heuland puede verse: BARreiro, A. (ed.) (1929), El viaje científico de Conrado y Cristián Heulanad a Chile y Perú, Sociedad Geográfica, Madrid, (la «Instrucción» ocupa las páginas 159-167); ARIAS DIvITO, J.C. (1978), La expedición científica de los hermanos Heuland 1795-1800 Cultura Hispánica, Madrid; y el catálogo de la exposición: La expedición mineralógica de los hermanos Heuland a Chile y Perú 1795-1800, Museo Nacional de Ciencias Naturales, CSIC, Madrid, 1987.

22 Véase RumEu DE ARMAS, R. (1979), «La Real Escuela de Mineralogía de Madrid (1789-1808)», Hispania, $\mathrm{n}^{\circ} 39$, p.311 (nota 33). Chabaneau expidió en Madrid un certificado de estudio al alumno Francisco Carbonell en su condición de «catedrático de la Real Escuela de Mineralogía de Indias establecida en esta corte», con fecha de 1 de agosto de 1790. 
en los secretos de la platina, para que una vez formados pasaran a gestionar la explotación de nuestros recursos en América. Debido al escaso interés de la juventud por cruzar el océano, la Escuela cambió su nombre por el de Real Escuela de Mineralogía ${ }^{23}$. Estuvo ubicada inicialmente en el local conocido como «Casa del platino» en la calle Hortaleza y a los dos años cambió su establecimiento a la calle del Turco (actual Marqués de Cubas), a un local que comprara el Estado para instalar la sucursal de la Real Fábrica de Cristales de San Ildefonso ${ }^{24}$.

En un piso vacante anejo al Real Almacén de Cristales, se instaló la Real Escuela de Mineralogía a cargo de Chavaneau ${ }^{25}$. Dentro de la misma institución se encuadraba el Laboratorio Químico-Metalúrgico, o Laboratorio del Platino, establecimiento dedicado a los experimentos para la purificación del platino, con la que coordinaba sus actividades y donde los alumnos de la Escuela de Mineralogía podían realizar sus prácticas.

Un profesorado competente y una dotación especial, garantizaban una prolija actividad científica, paralela a una actividad docente que incluía en dos cursos de duración disciplinas tales como Mineralogía (identificación, clasificación y distribución de minerales), Geognosia (formación e historia de rocas y minerales), Metalúrgica y Geometría subterránea. La producción de la platina, se vió acompañada por el descubrimiento de la magnesita de Vallecas y de la venturina de San Fernando y la aparición de los Elementos de Ciencias Naturales ${ }^{26}$ de Chavaneau.

En torno a 1791 se amplió la plantilla ante el eminente crecimiento de la institución. Entró a formar parte de ella el alemán Christian Herrgen (1760-1816)27, para hacerse cargo del Laboratorio del Platino, dado que entre sus méritos contaba con una sólida formación de química ${ }^{28}$.

Clavijo conoció a Herrgen y su trato le convenció de sus conocimientos en mineralogía. Propuso entonces en 1796 a Herrgen como sucesor de Juan Palafox Rovira en su cargo de Colector del Real Gabinete de Historia Natural ${ }^{29}$. Este hecho tendrá

23 Ibidem, pp.311-312.

$24 \mathrm{Ibidem}$. En las mismas fechas, el Ministerio de Hacienda y la Junta general de Comercio y Moneda instalaron, tambien en la calle del Turco, un Laboratorio de Química. Estaba dirigido por Domingo García Fernández y en él se realizaban el tipo de análisis, relacionados generalmente con la ley de las monedas, requeridos por dichas instituciones. Además se atendía la docencia de la química y su aplicación a la industria.

25 Chavaneau había tenido hasta entonces un ayudante, Joaquín Cabezas, profesor interino y magnífico fundidor.

26 Chabenau, F. (1790), Elementos de Ciencias Naturales. Imp. Vda de Ibarra, Madrid.

27 Una biografía y bibliografía de Herrgen puede verse en MAFFEI, E. y RUA FIGUEROA, R. (18712), vol.I, pp.351-354.

28 Archivo Histórico Nacional (AHN) Hacienda. Registro de Reales Ordenes. Libro 10.832, fol. 153. También en Rumeu de Armas, opus cit., pp.314.

29 BARREIRO, A. (1992), pp. 105. 


\section{DOLORES PARRA Y FRANCISCO PELAYO}

una gran incidencia, ya que la estrecha relación entre ambos contribuyó a la institucionalización de la mineralogía, principal afán de Herrgen a lo largo de su vida. Además, este cargo significaba un apoyo sólido a sus anhelos por parte de una institución capaz de canalizar sus interes por afines, en un momento en el que el floreciente desarollo de la mineralogía veía amenazada su continuidad.

Así, en 1797 Chavaneau solicitaba al gobierno su segunda licencia para ausentarse de España temporalmente, ocasión que aprovechó para no volver al desempeño de sus funciones ${ }^{30}$. Proust acordó entonces en Madrid con Herrgen y Clavijo que resultaría más eficaz aunar en una sola las diversas escuelas químicas que había en Madrid, ubicándola en la calle del Turco bajo su dirección, tras abandonar su cargo en el Real Laboratorio Químico de Segovia. Clavijo sería el personaje encargado de llevar adelante esta idea, que se aprobaría en $1799^{31}$.

\section{EL REAL ESTUDIO DE MINERALOGÍA DE MADRID}

En este mismo plan de actuaciones, Herrgen y Clavijo aprovecharon para impulsar la mineralogía, proponiendo la creación de una Escuela de Mineralogía. Se trataba esta vez de institucionalizar de manera definitiva en España la enseñanza mineralógica, al igual que la botánica o la química.

Así, en la nueva etapa que se había iniciado en el Gabinete en 1786, se había pretendido por parte de la Secretaría de Estado que la institución no sólo se dedicara a recoger y exponer objetos singulares de historia natural, sino que además se convirtiera en un centro dedicado a la enseñanza de las ciencias naturales. Así, junto con el nombramiento de director, a Izquierdo se le comunicaba que debía impartir clases de historia natural, mientras que Francisco Angulo lo haría de química. Clavijo propuso en un memorial de 1798 dirigido a la Secretaría de Estado que, al igual que se había hecho para la historia natural y la química, se impartieran clases de mineralogía. Pero para ello era necesaria la contratación de un profesor que se encargara de impartir esta materia ${ }^{32}$.

En este memorial Clavijo sostenía que el Gabinete poseía en ese momento el suficiente número de ejemplares para que se pudiese considerar como uno de los más completos de Europa. Sin embargo, esta riqueza sólo servía en ese momento para

30) Rumeu de Armas, A. (1979), pp.320.

3) Acerca de la institucionalización de la química en España puede verse GAGO, R. (1984), «La enseñanza de la química en Madrid a finales del siglo XVIII» Dynamis, 4, 1984, pp. 277-300.

32 AMNCN, Oficio de Josef Clavijo Fajardo dirigido al Secretario de Estado Francisco Saavedra, fechado en Aranjuez el 3 de junio de 1798: «Medios de hacer util para la prosperidad de la Nacion Española el R'. Gabinete de Historia Natural». 
«entretener la ociosidad o la curiosidad de mujeres, niños y hombres que no saben en que emplear el tiempo». Clavijo se quejaba de que existiesen profesores y laboratorios de química en Madrid y Segovia - le parecía sumamente doloroso que hubiera un laboratorio en la localidad castellana donde poca o ninguna utilidad podían dar a la Nación-, y sin embargo en más de veinte años no se hubiese pensado en tener un profesor de mineralogía. Y más porque, como consideraba Clavijo, el estudio de esta ciencia debía preceder al de la química, ya que era tan importante como esta disciplina para la economía.

Clavijo y Herrgen contaban con un programa de actividades que justificaban este fin y que registraron exhaustivamente en el reglamento de régimen interno que redactaron conjuntamente y por el que debería regirse el funcionamiento de la Escuela ${ }^{33}$. Entre ellas figuraba la creación de una colección mineralógica sistemática que acompañara la impresión y la traducción de la Orictognosia escrita en alemán por D. Juan Federico Guillermo Widenmann (Madrid, 1797-1798) ${ }^{34}$, aportación científica de carácter teórico que gozó de gran aceptación pero que estaba por sí sola falta del soporte experimental.

La traducción de la obra de Johann Friedrich Wilhelm Widenmann (1764-1798), miembro del Consejo de Minas del ducado de Würtemberg, había sido realizada por el propio Herrgen.

En el «Aviso del traductor» de Herrgen, se justificaba la traducción porque se consideraba la obra más moderna, clásica y completa en su género, y la más adecuada para conocer los minerales y los fósiles. Además, proporcionaba a los españoles «un idioma científico, fijo, uniforme y análogo al que los sabios extranjeros han establecido desde que se introdujo en las escuelas de Hungría y Alemania».

En la introducción se dividía a la mineralogía, siguiendo a A. G. Werner (17491817), en varias disciplinas: orictognosia - a más importante, ya que se encargaba de la determinación y nomenclatura de los minerales atendiendo a sus propiedades físicas y a su análisis químico-, química mineralógica, geognosia, geografía mineralógica y mineralogía económica.

Además, viajes mineralógicos, recolección y descubrimiento de nuevas producciones de nuestro suelo, clases, traducción de publicaciones sobre el tema que se producían en Europa, descripciones, catálogos, inventario, etc., formaban parte de

33 AMNCN, «Cátedra de Mineralogía», Leg.1, carp.2, año 1798.

${ }^{34}$ Sobre la publicación en España de obras científicas de influencia werneriana, LAFUENTE, A.; Puig-Samper, M.A.; Hidalgo, E.; Peset, J.L.; Pelayo, P.; y Sellés, M., «Producción científica española durante el siglo XVIII: nuevos paradigmas y demanda profesional. Literatura werneriana» en Aguilar Piñal, F. (Coord.) Historia Literaria de España: el Siglo de la Ilustración, CSIC - Ed. Trotta (en prensa). 
este proyecto de Clavijo y Herrgen que comenzó a ser llevado a la práctica hasta convertirse en una realidad, casi en su totalidad.

El proyecto comenzó a concretarse apenas transcurrido un año desde que Chavaneau abandonara sus funciones, al aprobarse el establecimiento de la Escuela de Mineralogía, prueba de la eficacia y profesionalidad de sus impulsores. La nueva institución se llamó Real Estudio de Mineralogía y para su establecimiento se habilitó la antigua casa que habitara Chavaneau en la calle del Turco, junto a la Fábrica de Cristales, por estar al lado del Laboratorio de Química.

Conseguido este objetivo, faltaba materializar el deseo de Clavijo de hacer la Escuela dependiente del Real Gabinete de Historia Natural. Esto se lograría tras superar algunos inconvenientes logísticos y burocráticos, tales como la falta en las dependencias del Real Gabinete de Historia Natural de un laboratorio donde se pudieran realizar experimentos, o la dependencia de la nueva Escuela del Ministerio del Estado, que imposibilitaba a Herrgen para trabajar en dicho laboratorio, por estar éste adscrito al Ministerio de Hacienda. El primero quedaba solventado con la resolución de abrir un único laboratorio de química en Madrid, en el que fuera el Laboratorio Químico-Metalúrgico de Chavaneau.

Ese mismo año, Clavijo anunciaba la publicación de un revista periódica titulada Anales de Historia Natural, en virtud de la gran cantidad de material que había preparado $^{35}$. Pero el interés de la publicación se centraba en fomentar el estudio de la historia natural ${ }^{36}$ e incluirían temas mineralógicos, químicos y botánicos. El comité de redacción de esta obra lo formaron Herrgen, Proust, Domingo García Fernández y A. J. Cavanilles. En 1799 se publicó el primer número de la revista. Ésta cambió de nombre al segundo año de su publicación por el de Anales de Ciencias Naturales ${ }^{37}$.

Además de la publicación de la que era primera revista científica en España, el Real Estudio fue provisto de una copiosa dotación de libros, instrumental, productos químicos, mapas, barómetro y goniómetro. Como soporte teórico a la práctica experimental contaba con una rica biblioteca actualizada, en la que figuraban los últimos títulos publicados en Europa de mineralogía, geología y paleontología.

El 24 de marzo de 1800 Herrgen inauguró el curso de orictognosia en el establecimiento de la calle del Turco, junto a la Fábrica de Cristales, anunciándose en la Gaceta de Madrid con una semana de antelación. Abrió el curso con una lección inaugural que remitió al Secretario de Estado Mariano Luis de Urquijo.

\footnotetext{
35 AMNCN, «Cátedra de Mineralogía», Leg. 1, carp. 2, año 1798.

36 Ibidem.

37 Sobre la creación y la historia de esta primera revista científica española puede verse Fernández PÉrEZ, J. (ed.) (1993), Anales de Historia Natural 1799-1804, CICYT, t.I, «Estudio preliminar», pp.13-
} 130. 
Herrgen, a quien desde el principio se le había dado absoluta libertad para organizar sus enseñanzas, y reiterado la confianza de las autoridades con su aprobación en numerosas ocasiones, tenía un inteligentísimo programa encaminado a hacer la cátedra útil a la nación. El desarrollo de este programa comenzaba con instruir a sus discípulos en los conocimientos básicos «del ramo del terreno», la orictognosia y la geognosia. Para ello se había dedicado a lecciones con gran empeño y había traducido obras básicas como la Nueva teoría sobre la formación de las vetas de Werner. Con esta obra maestra y una porción de discursos que manda elaborar para este fin, quedaban organizados los materiales para la enseñanza de esa parte de la geognosia.

En 1802, Herrgen daba su segundo curso de mineralogía en el Real Estudio de Mineralogía de Madrid ${ }^{38}$. La materia del curso comprendía una primera parte teórica de la orictognosia en la que se explicaban las distintas clases del reino mineral: «tierras y piedras», «sales», «combustibles» y «metales» acompañadas de ejercicios prácticos que consistían en descripciones mineralógicas según el método de Werner. A estas lecciones de orictognosia, y como aplicación práctica, seguía el estudio de la descripción geognóstica de las rocas, «ciencia jamás estudiada en España» ${ }^{39}$.

El método de enseñanza seguido en este curso y un análisis del mismo fue presentado por Herrgen en un informe de mediados de 1803 al por entonces Secretario de Estado Pedro Cevallos ${ }^{40}$. Durante el curso, Herrgen explicó desde su comienzo en febrero de 1802 hasta el mes de junio la parte teórica de la orictognosia, comenzando con las clases de los minerales que comprendían las tierras, piedras y sales. Durante parte de junio se realizaron ejercicios prácticos, que consistían en descripciones mineralógicas según el sistema de Werner. En octubre explicó las dos restantes clases de los minerales, los combustibles y los metales, hasta terminar en diciembre la orictognosia. Posteriormente, entre mediados de abril y finales de mayo de 1803, explicó veinte lecciones de geognosia al reducido grupo de 5 ó 6 alumnos que habían estudiado la orictognosia y podían seguirle en su exposición de aquella disciplina.

La metodología didáctica empleada por Herrgen en sus cursos era muy dinámica y daba importancia a la participación activa de los alumnos en las clases. Así tenemos que, en 1803, los alumnos más aventajados pasaron pruebas como la exposición al público de algunos temas monográficos, que atestiguaban los progresos de esta enseñanza. Así, por ejemplo, Andrés Alcón dio una conferencia sobre las variedades de cuarzos y sus caracteres distintivos; Donato García lo hizo sobre el feldespato y sus variedades, la obsidiana y la «piedra perlada» centrando el tema en los nuevos yacimientos encontrados en España y México, y Francisco Escolar y Serrano habló

38 Herrgen, CH. (1802), «Discurso leido por D. Christiano Herrgen... en la apertura de sus lecciones mineralógicas en 1 de Febrero», Anales de Ciencias Naturales, V, pp.3-18.

39 AMNCN, «Cátedra de Mineralogía», leg. 1, carp. 5.

40) AMNCN, leg. nº 1, carp. $5^{\text {a }}$, fechado el 28 de junio de 1803. 
sobre los distintos tipos de carbonatos, incluído el de bario y sus caracteres diferenciales.

Herrgen citaba a los alumnos que asistían a sus clase. Pocos parece que fueron los discípulos cercanos a Herrgen durante sus años de enseñanza. Se conocen alrededor de una docena.

Entre los alumnos mencionados se encontraba Ramón de Gil la Quadra, del que decía Herrgen en el informe que había estudiado botánica con Cavanilles y química y mineralogía con Proust. Ese mismo año, 1803, Quadra publicaría un artículo en los Anales de Ciencias Naturales ${ }^{41}$. Posteriormente se dedicaría a la política siendo nombrado sucesivamente vocal de la Junta de Protección del Real Gabinete de Historia Natural (1815), consejero honorario de Estado, ministro de la Gobernación de Ultramar (1820-1821), ministro de la Gobernación del Reino, Marina y Comercio $(1836-1837)^{42}$.

El discípulo más cercano de Herrgen fue Martín de Párraga, a quien el geólogo alemán le preparó como su sucesor en la enseñanza de la mineralogía. Estuvo pensionado, en torno a 1803, en Freiberg y Dresde. Fue nombrado en octubre de 1806 profesor de dicha asignatura en Gabinete ${ }^{43}$. Publicó dos artículos y dos traducciones en los Anales ${ }^{44}$.

Herrgen comentaba de Bernardo Canga Argüelles que era bibliotecario y archivero del Departamento de Fomento y Balanza y que había publicado un artículo en $1802^{45}$.

En su informe Herrgen citaba también a un tal D. Gregorio, que era ayudante de Proust en la cátedra de Química; a Leonardo Vidal, empleado en las fundiciones de artillería; a José $\mathrm{M}^{\mathrm{a}}$ García Rodrigo, que junto con el anterior iban a la escuela de Proust; a Ramón Espiñeyra, protegido de Cevallos y pensionado con 6.000 reales anuales, quien realizaba las labores de ayudante de Herrgen. Espiñeyra fue autor de

41 GIL DE LA QUADRA, R. (1803), «Introducción a las tablas comparativas de todas las sustancias metálicas...», Anales de Ciencias Naturales, VI, pp. 17-46. También se le debe «Notas al Ensayo de mineralogía de D. Josef Brunner», ibidem, VII, pp.323-334.

42 Maffei, E. y RuA FigueroA, R. (1871-2), vol. II, p.74.

4.3 Ibidem, vol.1I, p.15.

44 Los artículos fueron: «Piedra caliza folicular de las cercanías de Madrid», Anales de Historia Natural, II, 1800, pp.175-176; y «Noticia del descubrimiento de una mina de grafito en el reyno de Aragón», ibidem, V, 1802, pp.22-25, mientras que las traducciones: «Descripción de un gravímetro o instrumento a propósito para medir la gravedad específica de los sólidos y los fluidos, por el ciudadano Guiton», ibidem, II, pp.317-335 y «Carta del barón A. HumBOLDT al ciudadano Delambre...», ibidem, IV, 1801, pp.199-206.

45 Herrgen, Ch. (1803), «Descripción mineralógica de la Blenda carbonosa del Puerto de Pajares», Anales de Ciencias Naturales, VI, pp.19-22. 
dos pequeños artículos en los Anales y de una memoria sobre los compuestos y criaderos metálicos ${ }^{46}$.

El último que citaba Herrgen en su informe era Alejandro Vicente Espeleta, a quien le encargó, junto con Juan Modesto Peringuer, el estudio de los minerales de Chile y la traducción de la nomenclatura química de la obra de L. Brugnatelli47 .

Además de estos alumnos, los más aplicados al estudio de la mineralogía, Herrgen comentaba que también habían asistido de manera muy regular a sus clases un cierto número de aficionados, entre los que se encontraban algunos personajes de clase social acomodada, como el marqués de Zilleruelo, Matías Collado o Gaspar de Montagut, de quienes decía que le habían honrado con su asistencia continua. Finalmente también asistieron los curiosos dispuestos a pasar el rato en cualquier lección pública de cualquier cátedra de la corte, aunque no muy agradable para los catedráticos. El alumnado era siempre muy numeroso a principio de curso quedando las promociones finalmente reducidas a treinta o treinta y cinco personas, otros que carecían de talento y de una mínima preparación científica, además de algunos curiosos que sólo asistían a las lecciones públicas para pasar el rato, lo cual era muy común, decía, entre las cátedras que se impartían en la Corte.

Otro discípulo de Herrgen fue Enrique Umaña, natural de Santafé de Bogotá y relacionado con la expedición botánica organizada por José Celestino Mutis (1732$1808)^{48}$. Umaña, tras estudiar con Herrgen en el curso del año 1800, había pasado a París para ampliar estudios en Historia Natural. Allí se dirigió a la École des Mines y con el apoyo de Rene-Just Haüy (1743-1822), profesor de mineralogía en esta institución y anteriormente en el Muséum National d'Histoire Naturelle (1802) y en la Sorbonne (1809), y de varios profesores de las instituciones científicas parisinas, solicitó ayuda económica del gobierno español para la compra en la capital francesa, a un precio que rondaba los 6.000-8.000 reales, de "una colección sistemática de minerales conocidos, y de los modelos de sus cristalizaciones", con el objeto de iniciar la enseñanza de la mineralogía en Nueva Granada ${ }^{49}$.

Tras ser consultado Herrgen para que diera su opinión autorizada sobre esta compra, respondió desaconsejándola, ya que, decía, una buena colección de minerales,

46 «Amatista de Mallorca», Anales de Historia Natural, II, 1800, pp.176-177; «Calcedonia de Panamá», ibidem, II, 1800, pp.315-317 y «Compañeros y criaderos de las especies metálicas..», Anales de Ciencias Naturales, VI, 1803, pp.47-117.

47 «Tabla de la nomenclatura moderna de la Química para el uso del laboratorio de la Universidad de Pavía en el año IX, por el Sr. Brugnatelli, traducida por D. Alexandro Vicente Ezpeleta y D. Juan Modesto Peringuer», Anales de Ciencias Naturales, V, 1802, pp.38-56.

48 SOBRE E. Umaña puede verse AmAYA, J.A. (1995), «La traduction espagnole inedite du Tableau du Regne vegetal de Ventenan», en LAISSUS, Y. (ed.), Les naturalistes français en Amérique du Sud $X V r^{\prime}-X I X e^{\prime \prime}$, Éditions du CTHS, Paris, pp.167-182.

49 $\mathrm{AMNCN}$, leg. $\mathrm{n}^{\mathrm{o}}$ 1, Carp. $4^{\mathrm{a}}$. 
como la que describía Umaña, no se podía encontrar por ese precio en ningún lugar de Alemania y mucho menos en París ${ }^{50}$.

En el informe de Herrgen a Cevallos correspondiente a 1804 sobre la finalización del curso de orictognosia, mencionaba también a los citados Donato García (17821855) y Andrés Alcón (1782-1850), además de Pedro Pablo Arrieta, Pedro Rodríguez de Novoa y Manuel Mariano de León.

Hay que mencionar también entre los discípulos de Herrgen a Juan Sánchez Cisneros. Fue un militar que perteneció a la Academia de Ciencias Naturales y Artes de Barcelona, a la Sociedad Patriótica de Sanlúcar de Barrameda y a la Sociedad Económica de Valencia. Sánchez Cisneros solicitó su entrada en la Academia de Ciencias Naturales y Artes de Barcelona en 1799, presentando ese mismo año una memoria titulada «Discurso físico-natural sobre la formación de las montañas calizas y su origen y el descubrimiento en la de Gibraltar de una petrificación animal que se conserva en el Real Gabinete del Laboratorio Chimico de Madrid». En ella expuso las opiniones del químico Richard Kirwan (1733-1812) sobre el origen y formación de las montañas. Una obra suya, los Elementos de Mineralogía, sería traducida al castellano en 1789 por Francisco Campuzano, comisario de Provincia de Marina.

En las actas de la Real Sociedad Económica de Valencia, en donde desempeñó la vicesecretaría, publicó algunas memorias mineralógicas entre 1803 y 1805: sobre las piedras del gabinete de dicha institución, sobre los minerales de Valencia y sobre los caracteres del carbón mineral, en donde adopta la clasificación de Werner ${ }^{51}$.

Sánchez Cisneros publicó en 1803 en los Anales $^{52}$ un artículo que envió a Herrgen sobre la cueva de la Berquilla en Murcia. Parece que fue una respuesta al comentario de Herrgen en su Descripción geognóstica de las rocas... (1802), sobre la ausencia en España de descripciones de cuevas, algo muy común entre los románticos alemanes. Sánchez Cisneros sería autor en 1819 de los Elementos sublimes de geografía fisica.

Herrgen logró elevar la enseñanza de la mineralogía en España a una altura superior a la que gozaba en París, y esto no sólo lo reconocía él sino también los naturalistas franceses en sus publicaciones acerca de su atraso en la mineralogía, y sobre la necesidad de incorporarse al sistema de los alemanes ${ }^{53}$.

Entre los objetivos de la cátedra de Herrgen se encontraron la defensa del cambio en el aprovechamiento de los recursos minerales mediante la investigación y la enseñanza, según la línea seguida en Sajonia. Efectivamente, faltaban por integrarse las enseñanzas de minería práctica y minerometalurgia - la minería práctica comprendía

50) Ibidem.

51 MAFFeI, E. y RUA FigueroA, R. (1871-2), vol II, pp.137-139.

52 «Descripción de la cueva de la Berquilla», Anales de Ciencias Naturales, VI, 1803, pp.171-182.

5.3 AMNCN, «Cátedra de Mineralogía», leg. 1, carp. 4, Cristiano Herrgen, 14 mayo 1801. 
los estudios de geometría subterránea y de mecánica aplicados al laboreo de minas, así como todo lo relativo a los procesos mecánicos a que se deben someter los minerales extraídos de la tierra antes de estar preparados para el comercio-, que completaban el abanico de ramas de la mineralogía ${ }^{54}$. Estas dos materias que restaban eran, a juicio de Herrgen, las más interesantes, por ser, en definitiva, las que permitirían el aprovechamiento de los recursos naturales y la utilización primaria del suelo, como fuente de materias primas capaces de utilizar y o transformar las actividades de la población en beneficio propio. Herrgen pretendía para ello la colaboración de la Escuela de Minas de Almadén, donde la creación de una cátedra de Minería Práctica y Metalurgia y la capacidad de acogida del territorio para dichas actividades asegurarían la resolución de los aspectos prácticos de estos discípulos conectados y coordinados directamente con las impartidas en Madrid. Así los cadetes de la Escuela de Minas de Almadén podían acudir a Madrid a recibir clases teóricas. Era necesario pues, contar con la colaboración del Ministerio de Hacienda y el compromiso de no asignar cargos que exigieran este tipo de conocimientos más que al personal acreditado mediante exámenes públicos, lo que haría de la mineralogía una carrera perceptiva para el desempeño de cualquier puesto técnico en la explotación de minas.

Con la invasión napoleónica, el local que ocupaba la Escuela de Mineralogía fue vendido por los franceses. Herrgen trasladó todo el material al Real Gabinete de Historia Natural donde quedó almacenado en cajas en las buhardillas y sótanos. Desapareció así la Casa de la platina y todo el metal que allí se almacenaba. Tras marcharse los franceses de Madrid, Herrgen recibió una Real Orden para que continuara sus lecciones.

El 1 de octubre de 1815 se estableció por Real Orden el «Plan para la Enseñanza de Ciencias Naturales», por el que se creaba un único establecimiento para la enseñanza de las ciencias naturales, que se llamaría Real Museo de Ciencias Naturales. Esta nueva institución unía el Real Gabinete de Historia Natural, el Jardín Botánico, el Museo, el Laboratorio Químico y el Estudio de Mineralogía. El Plan establecía la creación de cinco cátedras, correspondientes a las disciplinas de «Botánica», «Mineralogía», «Química», «Cuadrúpedos, Aves y Peces» y «Reptiles, Insectos y Conchas», que contarían con un profesor, además de un asociado como ayudante ${ }^{55}$.

En 1816 murió Herrgen y la enseñanza de la mineralogía fue encargada al viceprofesor Donato García, que dos años después fue nombrado profesor en propiedad. Desde entonces, y hasta su jubilación en 1854, sería el encargado de la enseñanza de la mineralogía en el Museo de Ciencias Naturales de Madrid.

54 AMNCN, «Cátedra de Mineralogía», leg. 1, Carp. 5.

$55 \mathrm{AMNCN}$, «Cátedra de Mineralogía», leg. 1, carp. 13. 